\title{
Effect of Extender with or Without Centrifugation of Mongrel Dog Semen Preserved at Refrigeration Temperature (4 C)
}

\author{
Praveen Kumar ${ }^{1}$, Ankesh Kumar ${ }^{1}$, S. P. Singh ${ }^{1}$, J. K Prasad ${ }^{1}$, \\ D. Sengupta ${ }^{1}$, S. K. Sheetal ${ }^{1 *}$ and Pallav Shekhar ${ }^{2}$ \\ ${ }^{1}$ Department of Veterinary Gynaecology and Obstetrics, ${ }^{2}$ Department of Veterinary Medicine, \\ Bihar Veterinary College, Bihar Animal Sciences University, Patna, Bihar, India \\ *Corresponding author
}

\section{A B S T R A C T}

\section{Keywords}

Mongrel dog,

Centrifugation,

Prostatic fluid,

Refrigeration

temperature, Semen

preservation

Article Info

Accepted:

04 August 2020

Available Online:

10 September 2020
In the present study, 3 mongrel dogs were taken for semen collection. Total of 18 ejaculates were collected, 6 from each dog by digital manipulation. All the collected samples were randomly divided into three Groups viz. Group I (Non-extended semen), Group II (Semen extended with egg yolk tris citrate fructose extender) and Group III (Sperm pellet extended with egg yolk tris citrate fructose extender) and kept at refrigeration temperature $\left(4^{\circ} \mathrm{C}\right)$. In Group III semen is centrifuged at $720 \mathrm{xg}$ for 5 minutes by centrifuge machine Tarsons Spinwin MC05-R for making of sperm pellet. After centrifugation of semen, removed the supernatant from sample and the sperm pellet resuspended in egg yolk tris citrate fructose extender at room temperature and re-diluted semen samples were placed at refrigeration temperature $\left(4^{\circ} \mathrm{C}\right)$ for further semen evaluation on daily basis. The preserved semen were examined for individual progressive motility, live dead percent, sperm morphological abnormality, HOST (Hypo osmotic swelling test) and intact acrosome at each day of preservation till progressive motility goes down less than $40 \%$. We found that motility goes down below $40 \%$ on day 2 in group I and on day 4 in group II and group III. Further sperm live dead percent, HOST (Hypo osmotic swelling test) and intact acrosome were higher in Group II as compared to Group I and III.

\section{Introduction}

Dogs were the first species of animals in which semen was collected, artificial insemination performed and off-springs obtained successfully by Spallanzani in 1776 and still very little work has been done till date for the evaluation and preservation of dogs semen to fully exploit the genetic potential of the male animals. For successful of Artificial insemination technique, the most important step is preservation of semen. In case of dogs, the semen can be preserved at chilling $\left(4^{\circ} \mathrm{C}\right)$ and freezing temperature ($196^{\circ} \mathrm{C}$ ). To chill a sperm sample, the second sperm-rich fraction can be diluted with Triscitric acid-fructose diluent with $20 \%$ egg yolk in a proportion of 1:3 to 1:4 (Rijsselaere et al., 2011).

In order to preserve the fertilizing ability of spermatozoa from their own toxic byproducts, 
cold shock and osmotic shock during the chilling semen extender are added into the semen as well as also acts as a source of nutrition (Zorinkimi et al., 2017a). Extender should protect the spermatozoa from cold shock during cooling by adding of $20 \%$ egg yolk, it provides energy substrate (fructose or glucose) and maintain constant $\mathrm{pH}$ and osmolarity by adding buffers (England,1993).

Dog semen is normally ejaculated in three fractions. The first and third fraction originate from prostate gland and are not collected because prostatic fluid was shown to be unsuitable for preserving canine semen at $4^{\circ} \mathrm{C}$ and has harmful effects on spermatozoa during preservation (Rijsselare et al., 2002). Only the second sperm rich fraction is collected, however it is not always possible to avoid the admixture of other fractions. So centrifugation immediately after sperm collection is one of the methods to remove prostatic fluid that is unsuitable for preserving dog semen at $4^{\circ} \mathrm{C}$. Sperm parameters can be better by low-speed centrifugation of canine spermatozoa in a single density gradient (Dorado et al., 2013). Spermatozoa from different mammals showed different sensibility to centrifugation process.

Furthermore, species, breeds and individual variation are also important factors because the compositions of seminal plasma and sperm membrane varies greatly between species and individuals. Dilution of semen or removal of seminal plasma is believed to be necessary for prolonged storage (Pickett et al., 1975). Keeping in view of the above facts the present study is designed to study the effect of removal of prostatic fluid on semen preservation at refrigeration temperature.

\section{Materials and Methods}

The present research work was carried out in the Department of Veterinary Gynaecology and Obstetrics, Bihar Veterinary College, Patna Bihar in the month of February 2020 to July 2020. Experimental animal constituted 3 mongrel dogs of more than one year of age with normal libido having average body weight of 20- $30 \mathrm{kgs}$.

The dog had housed in kennel of Bihar Veterinary College, Bihar Animal Sciences University Patna and was kept on uniform diet (two times in day with ad lib access to drinking water) and management during the entire study. All animals were dewormed orally with Tab Skyworm ${ }^{\mathrm{R}}$ (Praziquantel, Pyrantel Emboate and Febantel, 1 tab per 10 $\mathrm{kg}$ b.wt) and also vaccinated for Rabies (RabigenMono $^{\mathrm{R}} 1 \mathrm{ml} \mathrm{s} / \mathrm{c}$ ) 15 days before the start of the experiment.

All three dogs trained for semen collection by mechanical stimulation. Semen was collected twice a week from all the 3 mongrel dogs by digital manipulation in the morning hours. Thus, a total of 18 ejaculates were collected, 6 from each dog. Semen from each dog were collected by digital manipulation method without harming or giving stress to the animal in a calibrated plastic vial connect with funnel after proper cleaning of prepuce and perineal region with antiseptic solution following the method described by Christiansen (1984) with slight modifications with using an estrous bitch as a teaser.

\section{Evaluation of semen}

After semen collection, the ejaculates were immediately transferred to the laboratory and stored at $37^{\circ} \mathrm{C}$ in a water bath for further evaluation of seminal attributes.

\section{Individual progressive motility}

Individual progressive motility of each semen sample was assessed as described by Herman and Madden (1953). A fine drop of diluted 
semen was placed on pre-warmed clean, dry glass slide $\left(37^{\circ} \mathrm{C}\right)$ and covered with cover slip. The percentage of progressively motile sperm was observed by examined under high power microscope (40X) and sperm motility was recorded from 0 to 100 on visual appraisal based on the percentage of progressive motile spermatozoa.

Motile sperm percentage $=\underline{\text { Total sperm }- \text { non motile/dead sperm }} \times 100$

Total sperm

\section{Live dead percent}

The percentage of live spermatozoa was estimated by using Eosin- Nigrosin staining technique described by (Mukherjee and Dott, 1960).Microscopic examination revealed head of live spermatozoa as white and dead spermatozoa as pink.

\section{Sperm morphological abnormality}

The percentage of Sperm morphology was estimated by using Eosin-Nigrosin staining technique.

\section{HOST (Hypo- osmotic swelling test)}

The functional integrity of the sperm membrane was determined by using a Hypoosmotic solution as per the method described by Jeyendran et al., (1984).

\section{Intact acrosome}

The intact acrosome was studied following the technique of staining with Giemsa stain.

\section{Semen preservation}

Egg yolk tris citrate fructose extender (EYTCFE) was used to dilute semen samples to be chilled.

\section{Composition}

TRIS-2.4gm,

Citrate acid monohydrate-1.3gm,

Fructose -1gm,

Egg yolk -20 ml,

Distilled water up to $100 \mathrm{ml}$,

Penicillin G potassium -100000 IU,

Streptomycin- 100 microgram and

$\mathrm{pH}$ adjusted to 6.8 .

Egg yolk tris citrate fructose extender (EYTCFE) was made different for each semen sample. Egg yolk and antibiotics were added immediately before use. The semen was diluted $1: 1$ or $1: 2$ and preserved at refrigeration temperature $\left(4^{\circ} \mathrm{C}\right)$.

\section{Semen centrifugation}

Immediately after semen collection and primary evaluation, semen is selected for centrifugation. The semen is centrifuged at $720 \mathrm{x} g$ for 5 minutes by centrifuge machine TarsonsSpinwin MC05-R. After centrifugation of semen, remove the supernatant from sample and re-suspended the semen pellet with a Tris egg yolk citrate fructose extender at room temperature. The tube containing the re-diluted semen samples were placed into beaker filled with water at room temperature. The beaker with the tubes was kept immediately at refrigeration temperature $\left(4^{\mathrm{O}} \mathrm{C}\right)$ for further semen evaluation on daily basis.

The preserved semen were examined for individual progressive motility, sperm live dead percent, sperm morphological abnormality, HOST (Hypo osmotic swelling test) and intact acrosome at each day of preservation till progressive motility goes down less than $40 \%$. Statistical analysis was done by SPSS version 20.0 using 2-way ANOVA. 


\section{Results and Discussion}

\section{Individual progressive motility}

The mean value of sperm individual progressive motility of different groups is presented in the Table 1 and Graph 1. We found that sperm motility ranges between $88.00 \pm 3.10$ to $92.5 \pm 1.70 \%$ at day 0 of semen evaluation which is in agreement with the findings of Zorinkimi et al., (2017b) who reported the progressive motility of mongrel dog semen of 42 ejaculates of semen by digital manipulation from 3 mongrel dogs and observed the over-all mean of progressive motility of mongrel dog semen was $95.30 \pm 1.65 \%$. Kadirvel (1998) also observed 36 ejaculates from 6 mongrel dogs and the mean sperm motility recorded $86.67 \pm 1.07$ with a range of 70 to 95 percent immediately after semen collection with also corroborate our findings. Our findings that in EYTCF (Egg yolk tris citrate fructose) extender motility reduces close to $40 \%$ at $4^{\text {th }}$ day of semen evaluation are in close similarity with the record of Rota et al., (1995), who reported that the mean motility of sperm preserved in egg yolk tris extender reduces gradually on preservation at $4^{0} \mathrm{C}$ and drop to about $53 \%$ on day 4 of evaluation.

Kadirvel (1998) observed 36 ejaculates from 6 mongrel dogs the average percentage of sperm motility reduces from $86.38 \%$ to $49.86 \%$ in day 0 to day 5 of semen preservation in EYT extender which is in close proximity with our finding i.e. sperm motility reduces from $92.50 \%$ to $39.16 \%$ in day 0 to day 4 of semen preservation in EYTCF extender. Biswas (2010) observed that in 18 ejaculates from 3 dogs of Alsatian breed the mean value of progressive motility recorded on day 3 of preservation were 59.666 in EYTF (egg yolk tris fructose) extender and 61 percent in EYTG (Egg yolk tris glucose) extender. It is found that progressive motility also decreases with EYTCF (Egg yolk tris citrate fructose) extender and sperm pellet extended with EYTCF extender samples preserved at $4^{0} \mathrm{C}$ but slower than normal preservation at $4^{0} \mathrm{C}$ in refrigerator.

\section{Live dead percent}

The mean value of percentage live spermatozoa of different groups is presented in the Table 2 and Graph 2. The present findings are in agreement with the findings of Kadirvel (1998) and Zorinkimi et al., (2017b) who reported that the mean percentage of live spermatozoa in mongrel dog semen was $90.43 \pm 1.24 \%$ and $87.84 \pm 1.8 \%$ in freshly collected semen (Day 0) respectively. Kadirvel (1998) reported that the average percentage of live sperm recorded on day 0,1 , $2,3,4$ and 5 days of preservation were 89.54 $\pm 0.76,86.44 \pm 0.84,80.75 \pm 0.90,74.65 \pm$ $0.99,68.87 \pm 1.58$ and $60.87 \pm 1.58$ respectively in EYT extender.

These findings are also in agreement with our findings. However, the motility reduces to $48.50 \pm 15.65 \%$ at $4^{\text {th }}$ day in group II (extended with EYTCF extender) but, Kadirvel (1998) reported $60.87 \pm 1.58 \%$ in EYT extender. These finding suggest that EYTCF extender is better for preservation of semen at $4^{0} \mathrm{C}$ in comparison to without extender in group I (Non extended semen) and group III (Sperm pellet extended with EYTCF extender).

\section{Morphological abnormalities of sperm}

The mean values of morphological abnormalities of spermatozoa of different groups are presented in the Table 3 and Graph 3. Morphological abnormalities found during study were abnormal head, middle piece defects, proximal protoplasmic droplets, tail abnormalities. 
Table.1 Individual progressive motility of spermatozoa at different days of interval in different groups $(\mathrm{N}=06)$

\begin{tabular}{|l|l|l|l|l|l|l|}
\hline Sl.No & Group & Day 0 & Day 1 & Day 2 & Day3 & Day 4 \\
\hline $\mathbf{1}$ & Group I & $88.33 \pm 2.78^{\mathrm{aA}}$ & $70.00 \pm 2.88^{\mathrm{bB}}$ & $36.33 \pm 1.20^{\mathrm{cB}}$ & & \\
\hline $\mathbf{2}$ & Group II & $92.50 \pm 1.70^{\mathrm{aA}}$ & $84.16 \pm 2.50^{\mathrm{aA}}$ & $72.83 \pm 3.96^{\mathrm{abA}}$ & $60.00 \pm 5.62^{\mathrm{abA}}$ & $39.16 \pm 13.19^{\mathrm{bcA}}$ \\
\hline $\mathbf{3}$ & Group III & $88.00 \pm 3.10^{\mathrm{aA}}$ & $80.33 \pm 4.63^{\mathrm{abAB}}$ & $71.66 \pm 4.22^{\mathrm{abA}}$ & $58.33 \pm 6.91^{\mathrm{bcA}}$ & $35.00 \pm 11.97^{\mathrm{cAB}}$ \\
\hline
\end{tabular}

Means bearing different superscripts differed significantly $(\mathrm{P}<0.05)$ row wise $(a, b, c)$ and column wise $(\mathrm{A}, \mathrm{B})$

Table.2 Percentage live spermatozoa on different days of semen evaluation in different groups $(\mathrm{N}=06)$

\begin{tabular}{|l|l|l|l|l|l|l|}
\hline SI.No. & Group & Day 0 & Day 1 & Day 2 & Day3 & Day 4 \\
\hline $\mathbf{1}$ & Group I & $93.83 \pm 2.13^{\mathrm{aA}}$ & $80.66 \pm 3.86^{\mathrm{bA}}$ & $63.33 \pm 2.47^{\mathrm{cB}}$ & & \\
\hline $\mathbf{2}$ & Group II & $94.91 \pm 1.20^{\mathrm{aA}}$ & $89.75 \pm 1.97^{\mathrm{aA}}$ & $82.83 \pm 2.77^{\mathrm{abA}}$ & $76.66 \pm 3.94^{\mathrm{abA}}$ & $48.50 \pm 15.65^{\mathrm{bA}}$ \\
\hline $\mathbf{3}$ & Group III & $90.33 \pm 1.33^{\mathrm{aA}}$ & $87.83 \pm 2.88^{\mathrm{aA}}$ & $80.33 \pm 3.74^{\mathrm{aA}}$ & $73.83 \pm 3.70^{\mathrm{aA}}$ & $25.66 \pm 16.33^{\mathrm{bAB}}$ \\
\hline
\end{tabular}

Means bearing different superscripts differed significantly $(\mathrm{P}<0.05)$ row wise $(\mathrm{a}, \mathrm{b}, \mathrm{c})$ and column wise $(\mathrm{A}, \mathrm{B})$

Table.3 Morphological abnormalities of sperm at different days of semen evaluation in different groups $(\mathrm{N}=06)$

\begin{tabular}{|c|c|c|c|c|c|c|}
\hline Sl.No. & $\begin{array}{c}\text { Morphological } \\
\text { abnormality }\end{array}$ & Day 0 & Day 1 & Day 2 & Day3 & Day 4 \\
\hline $\mathbf{1}$ & Group I & $9.50 \pm 0.65^{\mathrm{bAB}}$ & $11.66 \pm 0.76^{\mathrm{bAB}}$ & $15.00 \pm 0.68^{\mathrm{aA}}$ & & \\
\hline $\mathbf{2}$ & Group II & $8.25 \pm 0.77^{\mathrm{cB}}$ & $9.58 \pm 0.89^{\mathrm{cB}}$ & $11.16 \pm 1.07^{\mathrm{abA}}$ & $12.66 \pm 1.17^{\mathrm{abA}}$ & $13.00 \pm 2.77^{\mathrm{aAB}}$ \\
\hline $\mathbf{3}$ & Group III & $11.50 \pm 0.88^{\mathrm{cA}}$ & $13.33 \pm 1.14^{\mathrm{bA}}$ & $14.83 \pm 1.35^{\mathrm{abA}}$ & $15.25 \pm 1.16^{\mathrm{aA}}$ & $16.00 \pm 0.87^{\mathrm{aA}}$ \\
\hline
\end{tabular}

Means bearing different superscripts differed significantly $(\mathrm{P}<0.05)$ row wise $(\mathrm{a}, \mathrm{b}, \mathrm{c})$ and column wise $(\mathrm{A}, \mathrm{B})$.

Table.4 Hypo-osmotic swelling test percentage at different days of semen evaluation in different groups $(\mathrm{N}=06)$

\begin{tabular}{|l|l|l|l|l|l|l|}
\hline SI.No. & Host & Day 0 & Day 1 & Day 2 & Day3 & Day 4 \\
\hline $\mathbf{1}$ & Group1 & $93.83 \pm 1.88^{\mathrm{aA}}$ & $82.00 \pm 3.31^{\mathrm{bB}}$ & $76.66 \pm 2.55^{\mathrm{bB}}$ & & \\
\hline $\mathbf{2}$ & Group2 & $95.66 \pm 0.66^{\mathrm{aA}}$ & $91.83 \pm 1.75^{\mathrm{aA}}$ & $87.00 \pm 1.91^{\mathrm{aA}}$ & $81.33 \pm 2.44^{\mathrm{aA}}$ & $52.00 \pm 16.54^{\mathrm{abA}}$ \\
\hline $\mathbf{3}$ & Group3 & $95.83 \pm 0.14^{\mathrm{aA}}$ & $93.00 \pm 0.81^{\mathrm{aA}}$ & $88.66 \pm 1.40^{\mathrm{aA}}$ & $56.50 \pm 17.91^{\mathrm{abA}}$ & $28.50 \pm 18.03^{\mathrm{bAB}}$ \\
\hline
\end{tabular}

Means bearing different superscripts differed significantly $(\mathrm{P}<0.05)$ row wise $(\mathrm{a}, \mathrm{b}, \mathrm{c})$ and column wise $(\mathrm{A}, \mathrm{B})$.

Table.5 Acrosomal integrity percentage at different days of semen evaluation in different groups $(\mathrm{N}=06)$

\begin{tabular}{|c|l|l|l|l|l|l|}
\hline Sl. No & $\begin{array}{c}\text { Acrosome } \\
\text { integrity }\end{array}$ & Day 0 & Day 1 & Day 2 & Day3 & Day 4 \\
\hline $\mathbf{1}$ & Group I & $94.00 \pm 1.03^{\mathrm{aA}}$ & $88.50 \pm 1.15^{\mathrm{bA}}$ & $80.66 \pm 1.45^{\mathrm{cB}}$ & & \\
\hline $\mathbf{2}$ & Group II & $94.50 \pm 0.61^{\mathrm{aA}}$ & $89.50 \pm 0.50^{\mathrm{aA}}$ & $85.66 \pm 1.05^{\mathrm{aAB}}$ & $80.00 \pm 1.91^{\mathrm{aA}}$ & $52.16 \pm 9.64^{\mathrm{abA}}$ \\
\hline $\mathbf{3}$ & Group III & $95.33 \pm 1.14^{\mathrm{aA}}$ & $91.66 \pm 1.74^{\mathrm{aA}}$ & $87.16 \pm 1.77^{\mathrm{aA}}$ & $56.50 \pm 17.92 \mathrm{~b}^{\mathrm{aA}}$ & $28.50 \pm 18.02^{\mathrm{bAB}}$ \\
\hline
\end{tabular}

Means bearing different superscripts differed significantly $(\mathrm{P}<0.05)$ row wise $(\mathrm{a}, \mathrm{b}, \mathrm{c})$ and column wise $(\mathrm{A}, \mathrm{B})$ 
Graph.1 Individual progressive motility of spermatozoa at different days of interval in different groups $(\mathrm{N}=06)$

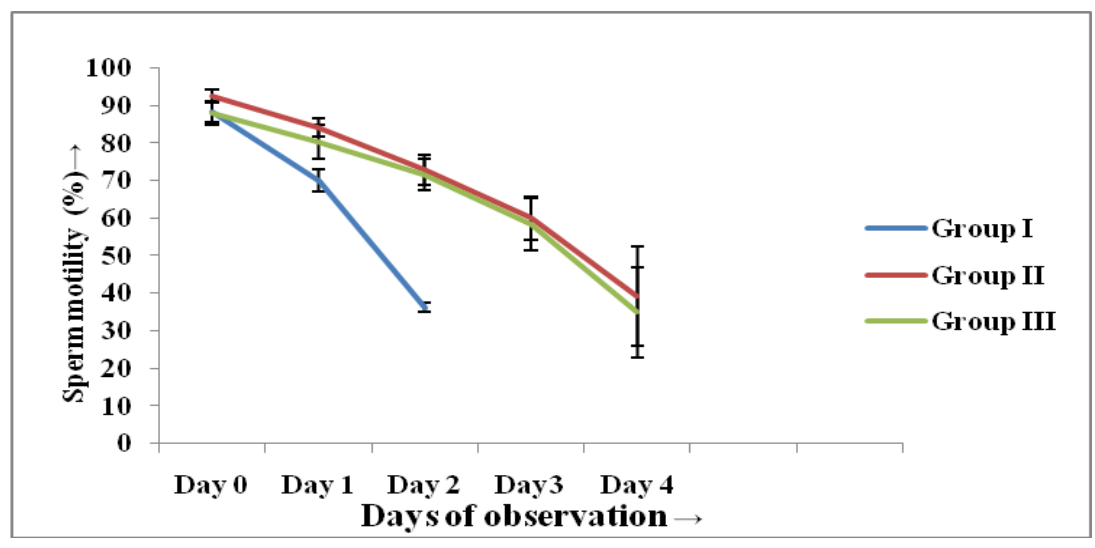

Graph.2 Percentage live spermatozoa on different days of semen evaluation in different groups $(\mathrm{N}=06)$

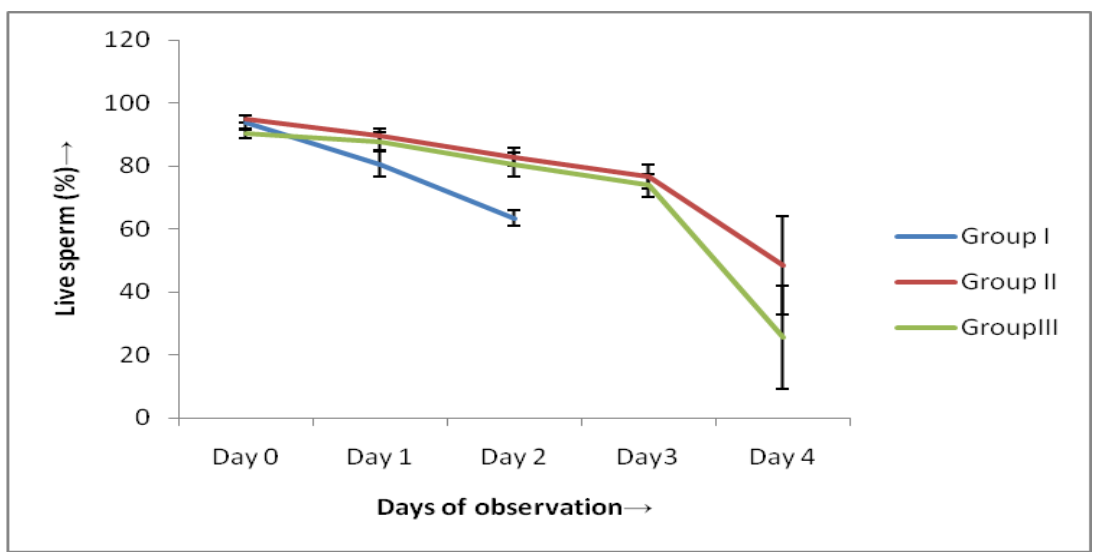

Graph.3 Morphological abnormalities of sperm at different days of semen evaluation in different groups $(\mathrm{N}=06)$

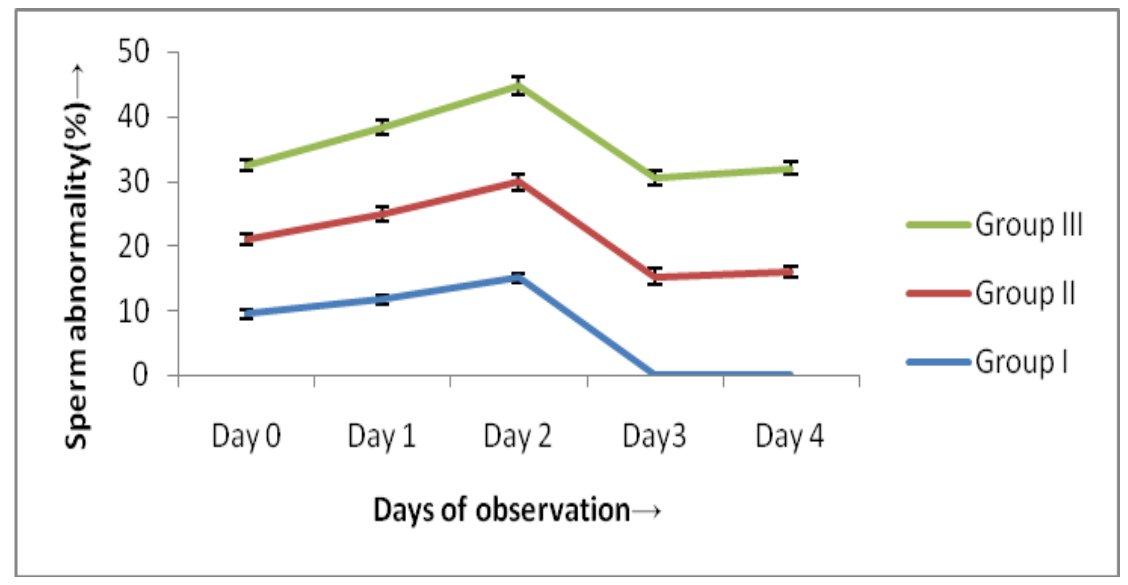


Graph.4 Hypo-osmotic swelling test percentage at different days of semen evaluation in different groups $(\mathrm{N}=06)$

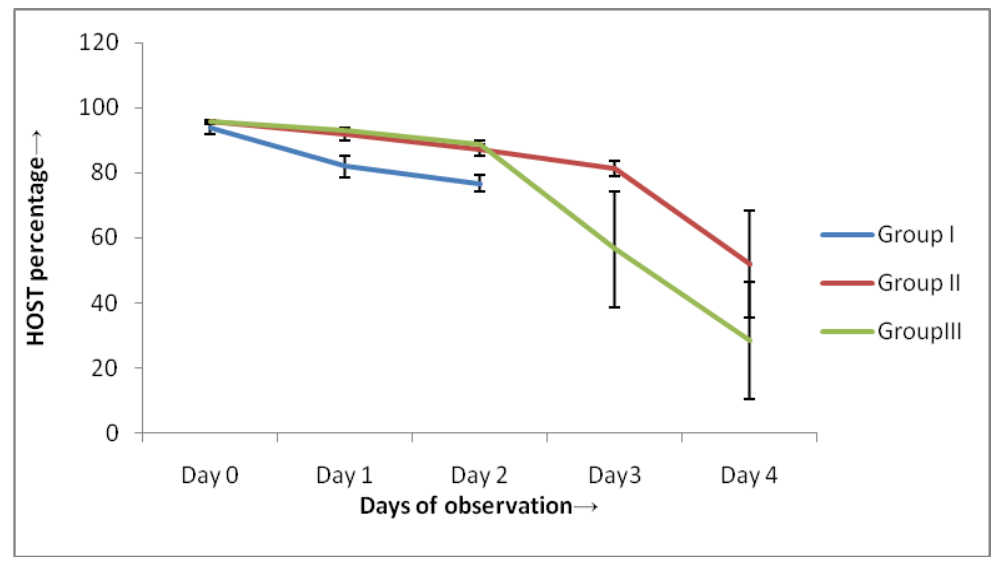

Graph.5 Acrosomal integrity percentage at different days of semen evaluation in different groups $(\mathrm{N}=06)$

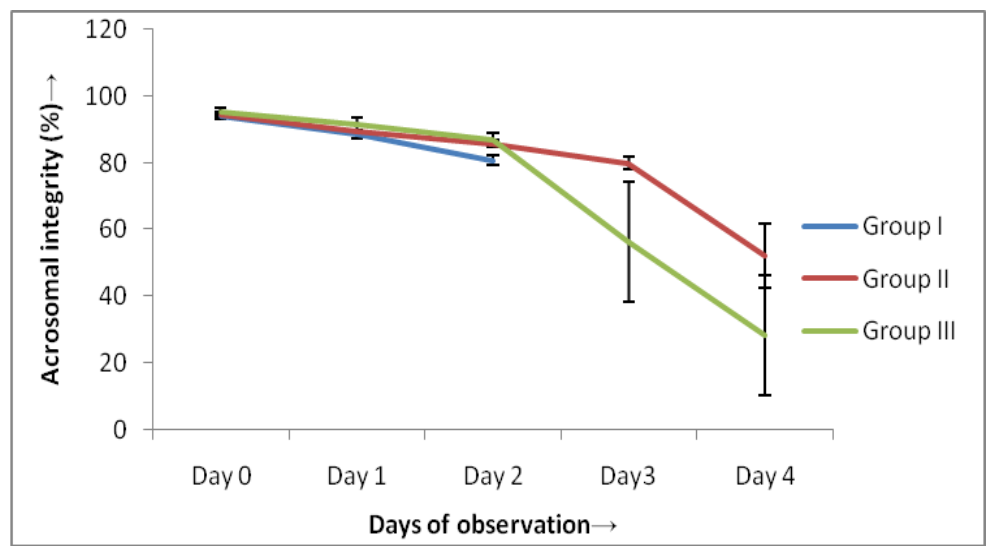

The present findings are in agreement with the report of Kadirvel (1998) who observed that 36 ejaculates from 6 mongrel dogs the average percentage of morphological abnormalities sperm recorded on day $0,1,2$, 3,4 , and 5 days of preservation were $8.82 \pm$ $0.50,11.65 \pm 0.64,14.17 \pm 0.75,16.67 \pm$ $0.85, \quad 19.35 \pm 0.99$ and $22.28 \pm 1.17$ respectively in EYT extender. However, in our experiment the rate of increase of abnormal spermatozoa with increasing days of semen preservation upto $4^{\text {th }}$ day is comparatively slower. The present findings are also in agreements with the reports of Rijsselaere et al., (2002), who reported that the mean normal sperm morphology in dog after 3 days of storage at $4{ }^{\mathrm{O}} \mathrm{C}$ the percentage of spermatozoa with a normal morphology was $85.3 \pm 18.7$ after centrifugation at $720 \mathrm{x}$ g. In group III (Sperm pellet extended with EYTCF extender) there is also increase in abnormal sperm morphology with increasing days of semen preservation after centrifugation in EYTCF (Egg yolk tris citrate fructose) extender. However, our present findings are not in agreement with the findings of Biswas (2010) who reported higher percentage of sperm abnormalities at day 3 of semen preservation in both egg yolk tris fructose and egg yolk tris glucose extenders. 


\section{HOST (Hypo-osmotic swelling test)}

The mean value of HOST (Hypo-osmotic swelling test) of different groups is presented in the Table 4 and Graph 4. The present findings are in agreement with the findings of Rota et al., (1995) and Zorinkimi et al., (2017b). Zorinkimi et al., (2017b) reported that the mean HOSTT - reacted sperm in mongrel dog semen was $93.27 \pm 0.53 \%$ in freshly collected semen. However, our present findings are not in agreement with the findings of Biswas (2010) who reported lower percentage of host reacted sperm at day 3 of semen preservation in both egg yolk tris fructose and egg yolk tris glucose extenders. Although, the percentage of HOST reacted spermatozoa decreases with increasing days of preservation in all the three groups, but comparatively slower in group II (extended with EYTCF extender). Thus group II is better for future fertility of sperm preservation. The swelling phenomenon in HOST is considered as a sign of functional integrity of the sperm membrane (Jeyendran et al., 1984).

The hypo osmotic swelling test (HOST) was developed to evaluate the functional integrity of the membranes of spermatozoa. The ability of the sperm tail to swell when exposed to hypo-osmotic conditions is a sign that water transport across the membrane occurs normally. Thus, the swelling phenomenon can be considered as a sign of functional integrity of the sperm membrane (Jeyendran et al., 1984). Spermatozoa with intact plasmalemma become swollen and show coiled tails. In dog spermatozoa, the hypo osmotic swelling was found to be positively correlated with sperm motility. Thus motility is an indicator of structural and functional competence of spermatozoa; therefore, the percentage of progressively motile spermatozoa is usually positively correlated with that of sperm plasma membrane integrity (Kumi-Diaka, 1993).

\section{Acrosomal integrity}

The mean value of Acrosomal integrity of different groups is presented in the Table 5 and Graph 5. The present findings are in agreement with the findings of Zorinkimi et al., (2017b) at day 0, who reported that the percentage of mean intact acrosome in mongrel dog semen was $97.37 \pm 0.77 \%$ in fresh semen. The present findings are also in agreement with the reports of Kadirvel (1998) who observed that the average percentage of acrosome damage recorded on day $0,1,2$ and 3 days of preservation were $8.88 \pm 0.58$, $12.96 \pm 1.04,17.19 \pm 1.48,21.29 \pm 1.76$ respectively in EYT extender preserved at $4^{\mathrm{O}} \mathrm{C}$. but we found that the acrosomal integrity severely reduces at day 4 in group II (extended with EYTCF extender). The mean acrosomal integrity reported in the present study at day 3 in group III(Sperm pellet extended with EYTCF extender) was $56.50 \pm 17.92 \%$ which was lower than the value reported by Rijsselaere et al., (2002), who reported $96.0 \pm 3.5 \%$ after 3 days of storage at $4^{\circ} \mathrm{C}$ and centrifugation at $720 \mathrm{x} \mathrm{g}$. However, good percentage of acrosomal integrity reported upto day $2(87.16 \pm 1.77 \%)$ in group III (Sperm pellet extended with EYTCF extender).

\section{Acknowledgements}

The authors would like to thanks to Director Research, Bihar Animal Sciences University and Dean, Bihar Veterinary College, BASU, Patna for his valuable cooperation and suggestions during research period. Financial assistance for this study was provided by Finance Comptroller Bihar Animal Sciences University Patna.

\section{References}

Biswas, P., 2010. Effects of different extenders on Canine Semen Stored at $4^{\circ}$ C. M.V.Sc. Thesis, West Bengal University of 
Animal and Fishery Sciences, Kolkatta.

Christiansen, J., 1984. Andrology of the normal male. In: Reproduction in the dog and cat.151 Edn. Bailliere Tindall, London, Philadelphia, Toronto, Mexico city, Rio de Janeiro, Sydney, Tokyo and Hong Kong. pp. 80-109.

Dorado, J., Alcaraz, L., Galvez M.J., Acha D., Ortiz I., Urbano M. and Hidalgo M. 2013. Single-layer centrifugation through PureSperm ${ }^{\circledR} 80$ selects improved quality spermatozoa from frozen-thawed dog semen. Anim. Reprod. Sci. 140: 232-240.

England, G.C.W., 1993. Cryopreservation of dog semen: a review. Journal of Reproduction and Fertility supplements. 4:243-255.

Herman, H.A., and Madden, F.W. 1953. The artificial insemination in dairy cattle.A hand book of laboratory manual.Lucas, Bros, Columbia, U.S.A.

Jeyendran, R.S., Van Der Ven, H.H., Perezpelaez, M., Crabo, B.G. and Zaneveld, L.J.D. 1984. Development of an assay to assess the functional integrity of the human sperm membrane and its relationship to other semen characteristics. J. Reprod. Fertil.70: 219228.

Kadirvel, G., 1998. Preservation of dog semen in three extenders at refrigeration temperature. M.V.Sc. Thesis, Kerala Agricultural University, Mannuthy, Thrissur, Kerala.

Kumi-Diaka, J., 1993.Subjecting canine semen to the hypo-osmotic test. Theriogenology. 39: 1279-1289.
Mukherjee, D.P., and Dott, R.M. 1960. Efeect of egg yolk citrate and egg yolk glycine dilutors on the morphology of bovine spermatozoa. J. Agric. Sci. 55: 225-228.

Pickett, B.W., Sulivan, J.J., Byers, M.S., Pace, M.M., Remmenga, E.E. 1975. Effect of centrifugation and seminal plasma on motility and fertility of stallion and bull spermatozoa, Fertil Steril. 26:167-173.

Rijsselaere, T., Van Den Berghe, F., Van Soom, A. 2011. Preservation and shipment of chilled and cryopreserved dog semen.VlaamsDierengeneeskundigTijdsc hrift. 80.

Rijsselaere, T., VanSoom, A., Maes, D., Kruif, A. 2002. Effect of centrifugation on in vitro survival of fresh diluted canine spermatozoa. Theriogenology.57:16691681.

Rota, A., Strom, B. and Linde-Forsberg, C. 1995. Effects of seminal plasma and three extenders on canine semen stored at $4{ }^{\circ} \mathrm{C}$.Theriogenology, 44(6): 885-900.

Zorinkimi, A., Ahmed, F.A., Lalrintluanga, K. and Kuotsu, N. 2017a. Effect of Different Extenders on the Quality of Mongrel Dog Semen Preserved at $5^{\circ} \mathrm{C}$ on the Basis of Hypo-Osmotic Sperm Swelling Test (HOSST). Int.J.Curr.Microbiol.App.Sci. 6(12): 961-964.

Zorinkimi, A., Ahmed, F.A., Lalrintluanga, K., and Kuotsu,N. 2017b. Characterization of Mongrel Dog Semen of Mizoram. Int.J.Curr.Microbiol.App.Sci. $\quad$ 6(12): 1140-1145.

\section{How to cite this article:}

Praveen Kumar, Ankesh Kumar, S. P. Singh, J. K Prasad, D. Sengupta, S. K. Sheetal and Pallav Shekhar. 2020. Effect of Extender with or Without Centrifugation of Mongrel Dog Semen Preserved at Refrigeration Temperature ( $4^{\circ}$ C) Int.J.Curr.Microbiol.App.Sci. 9(09): 351359. doi: https://doi.org/10.20546/ijcmas.2020.909.045 